\title{
Liquid and Gel Platelet Rich Plasma as Skin Healing Adjuvant
}

\author{
Plasma Rico em Plaquetas em suas frações líquida e em gel como adjuvantes da cicatrização cutânea \\ Tuane Nerissa Alves Garcez ${ }^{1,2}$, Helena Flores Mello², Priscilla Domingues Mörschbacher', \\ Paula Barros Terracianoㄹ, Viviam Pignone', Marta Justina Cioato ${ }^{3}$, \\ Elizabeth Obino Cirne-Lima ${ }^{2,4}$ \& Emerson Antonio Contesini ${ }^{5}$
}

\begin{abstract}
Background: In recent decades, many researches have been conducted on processes involved in tissue repairing, mainly in the development of resources and technology designed to improve the wound healing progress. Platelet rich plasma (PRP) derived from autologous blood is defined as a plasma volume with platelet concentration higher than physiological level. It is an autogenous and low cost source of growth factors, which are essential for tissue regeneration due to their angiogenic, mitogenic, and chemotactic properties. The aim of this study was evaluate two forms of PRP- liquid and gel - regarding their capacity to influence quality and repair time of standardized skin injuries.

Materials, Methods \& Results: New Zealand healthy rabbits were distributed in three groups $(n=6)$ : control group $(C G)$, liquid platelet rich plasma group (LIQPRP), and gel platelet rich plasma group (GELPRP). Acute skin lesions were inducted in two areas approximately $2 \mathrm{~cm}$ close to scapular edge and depth including epidermis, dermis, and hypodermis to external muscular fascia. Animals received treatment according to each group. Injuries were measured with digital pachymeter in two directions: longer length (l) and longer width (w), every two days. Areas and healing rates were calculated. Microscopic analysis samples were collected on days seven and 14 and evaluated through hematoxylin and eosin staining (HE) for global tissue examination, and through Masson's trichrome (MT) to collagen fibers present within the interstice. These analyzes considered: angiogenesis, inflammation infiltrated and collagen fibers quantity. Immunohistochemistry with anti-Ki-67 antibody was utilized for proliferative profile assessment. Kruskal-Wallis' non-parametric tests of independent samples was performed for comparison of values obtained through platelet count, referring to evaluation of platelet increase on treatments. Scar contraction rate (CR) was evaluated through Shapiro-Wilk's normality test, and then submitted to mixed models test. Results obtained by histopathological and immunohistochemistry were also evaluated by Shapiro-Wilk's normality test (for all tests a 5\% level of significance was considered). Platelet concentration achieved with liquid PRP was 8.64 and gel PRP reached 5.62 times higher than physiological values. Platelet increase mean for both groups was 7.95. No statistical significance was observed between groups. No side-effects or adverse reactions related to PRP usage were observed while study was conducted. Discussion: In the present study, there was a need to raise platelet poor plasma volume in order to obtain autogenous thrombin required for gel PRP. After this modification, a stable and reasonable platelet concentration gel was produced. However, this form of PRP application requires more time for sample preparation, increasing the production cost. Furthermore, injection of liquid PRP directly in the wound site activates platelets by generated substances due to needle perforation, and mainly due to tissue trauma generated at the lesion site. Relating to the therapies administered, gel PRP was considered more manageable, since 3D structure could easily adapt to wound site after simply deposition of it. Liquid PRP was administered with needle and syringe, which required the surgeon to be more careful and perform a slow injection in order to avoid any spill and loss of material. Furthermore, histopathological analysis did not point any clot traces formed by gel PRP dehydration, although it is not possible to ensure that the clot was eliminated, reabsorbed, or even removed by the animal. By this protocol, a stable and reasonable platelet concentration gel was produced. Further studies are encouraged as well as employment of alternative diagnostic tools, in order to better understand found results.
\end{abstract}

Keywords: skin, regenerative therapy, cell therapy, growing factors, platelets.

Descritores: pele, terapia regenerativa, terapia celular, fatores de crescimento, plaquetas.

Received: 2 0ctober 2015

Accepted: 25 April 2016

Published: 14 May 2016

${ }^{1}$ Programa de Pós-graduação em Ciências Veterinárias (PPGCV), Universidade Federal do Rio Grande do Sul (UFRGS), Porto Alegre, RS, Brazil. ${ }^{2}$ Laboratório de Embriologia e Diferenciação Celular, Hospital de Clínicas de Porto Alegre (HCPA)-UFRGS, Porto Alegre. ${ }^{3}$ Unidade de Experimentação Animal, Centro de Pesquisa Experimental, HCPA-UFRGS. ${ }^{4}$ Departamento de Patologia Clínica Veterinária, FaVet-UFRGS. ${ }^{5}$ Departamento de Medicina Animal, Faculdade de Veterinária, FaVet-UFRGS. CORRESPONDENCE: E.O. Cirne-Lima [ecirnelima@ gmail.com - Fax: +55 (51) 3308-7305]. Faculdade de Veterinária - UFRGS. Av. Bento Gonçalves n.9090, Bairro Agronomia. CEP 91540-000 Porto Alegre, RS, Brazil. 


\section{INTRODUCTION}

Platelets (PL) are blood cells that play an important role in homeostasis and are also one of the main sources of growth factors (GF). Several studies have shown that application of autogenous concentrates derived from platelet or platelet rich plasma (PRP) within a lesion area can accelerate tissue repair. This study aims to evaluate PRP usage in two forms: liquid and gel, in relation to their ability to influence quality and repair time of standard skin injuries in New Zealand rabbits.

\section{MATERIALS AND METHODS}

This research utilized 18 New Zealand healthy female rabbits, aged between four and five months and body mass between two and three kilograms, from a breeder registered to Unidade de Experimentação Animal from Hospital de Clínicas de Porto Alegre (UEA-HCPA).

\section{PRP Centrifugation Protocol}

Subsequently to pilot studies [6] a PRP preparation protocol was selected for application. Venipunction of jugular vein was utilized for blood sample collection, due to high volume needed. Thus, punction area was prepared with animals anesthetized, and $15 \mathrm{~mL}$ of blood was collected with a $25 \times 7$ needle attached to $10 \mathrm{~mL}$ syringe filled with $1 \mathrm{~mL}$ sodium citrate anticoagulant. Blood sample was stored in four flasks with $0.5 \mathrm{~mL}$ sodium citrate each and was immediately sent to Laboratório de Embriologia e Diferenciação Celular/HCPA for processing. One $\mathrm{mL}$ from whole blood sample was saved for platelet and other cellular counts. All procedure was conducted in laminar flow hood in order to keep an aseptic sample since the product would be administered to animals.

Protocol utilized for PRP obtaining proposes two centrifugations $\left(\text { Eppendorf }^{\circledR}\right)^{1}$, the first one at $250 \mathrm{~g}$ for $10 \mathrm{~min}$. After that, sample had three distinct layers: lower layer, containing red blood cells, intermediate layer, formed by a "cloudy zone", that included leukocytes and larger platelets, and upper layer, comprised by the plasma. Cloudy zone and plasma were collected, and the remaining volume was discarded. Collected fraction was submitted to a second centrifugation at $1000 \mathrm{~g}$ for $10 \mathrm{~min}$. By the end of this procedure, sample showed a pellet and the supernatant that was composed by plasma. Pellet was collected along with $150 \mu \mathrm{L}$ from plasma, which would both form PRP product after homogenization. Product was transferred to a microfuge tube and delivered to surgeon for immediate transplant.

Gel PRP was obtained following all steps above until the end of second centrifugation. Then, pellet was collected along with $2 \mathrm{~mL}$ of supernatant. A $0.5 \mathrm{~mL}$ aliquot was destined to platelet count and 1,5 $\mathrm{mL}$ aliquot was divided in two portions and transferred to 24-well plates, used as circular templates, and 150 $\mu \mathrm{L}$ of calcium gluconate was added for coagulation and gel formation. Products were sent to surgery center for immediate transplantation.

Platelet count was conducted at blood collection time and by the end of each concentration protocol in all samples, by automatic method. Platelet quantity reached in each sample and basal values were both analyzed.

\section{Surgical Procedure}

Animals under general anesthesia had the dorsal skin region delimitated in two areas approximately $2 \mathrm{~cm}$ close to scapular edge, about $6 \mathrm{~cm}$ apart from each other. Delimitated areas had the skin removed and injury depth including epidermis, dermis, and hypodermis to external muscular fascia.

\section{Therapeutic procedures}

Animals were randomly divided in three groups $(n=6)$ : control group $(\mathrm{CG})$, liquid platelet rich plasma group (LIQPRP), and gel platelet rich plasma group (GELPRP). Immediately after injury assessment, animals received the treatment according to group they composed (Figure 1).

\section{Sample obtaining}

After 7 or 14 days period, animals were submitted to a new surgery for total lesion area removal, including $2 \mathrm{~mm}$ beyond boundary of scar and neighboring healthy tissue. Scar from left side was removed at day 7 of post-surgery, and right side scar was collected at day 14 of post-surgery. Fragments were fixed in $10 \%$ formaldehyde, embedded in paraffin and processed.

\section{Morphometric evaluation}

Injuries were measured with digital pachymeter in two directions: longer length (1) and longer width (w), on days $0,2,4,6,7,8,10,12$, and 14 . These data allowed the calculation of lesion area in each evaluation. Wound contraction area $(\mathrm{C})$ was determined subtracting 
initial area $\left(\mathrm{A}_{1}\right)$ measured at day 0 (injury induction day), from lesion measurements obtained in the following evaluation days ( $\mathrm{x}=2,4,6,7,8,10,12$, and 14 ), so that $\mathrm{C}=\mathrm{A}_{\mathrm{x}}-\mathrm{A}_{1}$. Scar contraction rate $(\mathrm{CR})$ was assessed based on previous results, where $\mathrm{CR}=\mathrm{C} \times 100 / \mathrm{A}_{1}$.

\section{Microscopic evaluations}

Histological sections were stained by Hematoxylin and Eosin (HE) technique, for global evaluation of tissue slices, and by Masson's Trichrome (MT), to examine presence of collagen fibers.

In order to compare the different treatments we analyzed histological sections as follows: angiogenesis, shown by granulation tissue, based on newly formed vessels and fibroblasts; inflammatory infiltrate, by presence and quantity of mononuclear and polymorphonuclear cells; and collagen fibers quantity. Proliferative profile evaluation was performed by immunohistochemistry analysis with anti-Ki-67 antibody. Analyzes were evaluated by categorical variable: strong, moderate, and weak.

\section{Statistical Analysis}

Kruskal-Wallis' non-parametric tests of independent samples were utilized for comparison of values obtained through platelet count, referring to evaluation of platelet increase on liquid and gel PRP treatments. Scar contraction rate (CR) was evaluated through Shapiro-Wilk's normality test, and then submitted to mixed models test. Obtained results by histopathology and immunohistochemistry analysis were compared by the same test. All tests considered a significance level of $5 \%(P<0.05)$.

\section{RESULTS}

\section{Platelet count}

All animals treated with PRP, regardless of the form (liquid or gel), had basal platelet count determined for further analysis of platelet increment reached through concentration protocol. Platelet concentration achieved with liquid PRP was 8.64 times higher than physiological values (mean of basal platelet count from all samples), and gel PRP reached 5.62 times more platelet concentration than physiological values. Platelet increase mean for both groups was 7.95. No statistical significance was observed between groups.

\section{Morphometric evaluation}

Measurements at days $0,2,4,6,7,8,10,12$, and 14 allowed calculation of lesion area (larger length versus larger width) and wound contraction area (C), subtracting initial area $\left(\mathrm{A}_{1}\right)$ determined on day 0 (injury induction day), from lesion area obtained on following days of evaluation ( $\mathrm{x}=2,4,6,7,8,10,12$, and 14), so that $\mathrm{C}=\mathrm{A}_{\mathrm{x}}-\mathrm{A}_{1}$. Scar contraction rate $(\mathrm{CR})$ was evaluated based on previous results, where $\mathrm{CR}=\mathrm{C} \times 100$ / $\mathrm{A}_{1}$ (Figures $2 \& 3$ ).

Histopathological parameters (inflammatory reaction, collagen deposition, and angiogenesis) did not show difference in group means at days 7 and 14 . Immunohistochemistry parameters referring to epithelial and fibroblast proliferation mean percentages revealed significant difference between LIQPRP group and CG at day 14 (Figure 4).

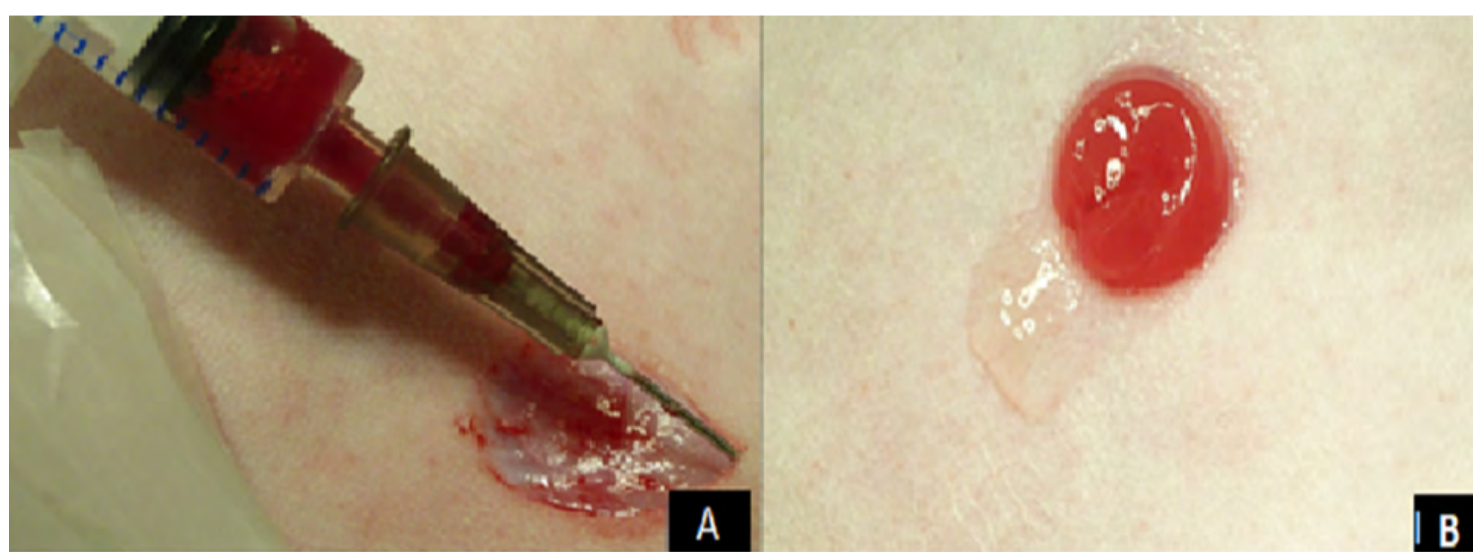

Figure 1. Therapeutic procedures executed after skin injury induction in rabbits. (A) Liquid platelet rich plasma injection in $1 \mathrm{~mL}$ final volume. (B) Gel platelet rich plasma administered on the wound site. 


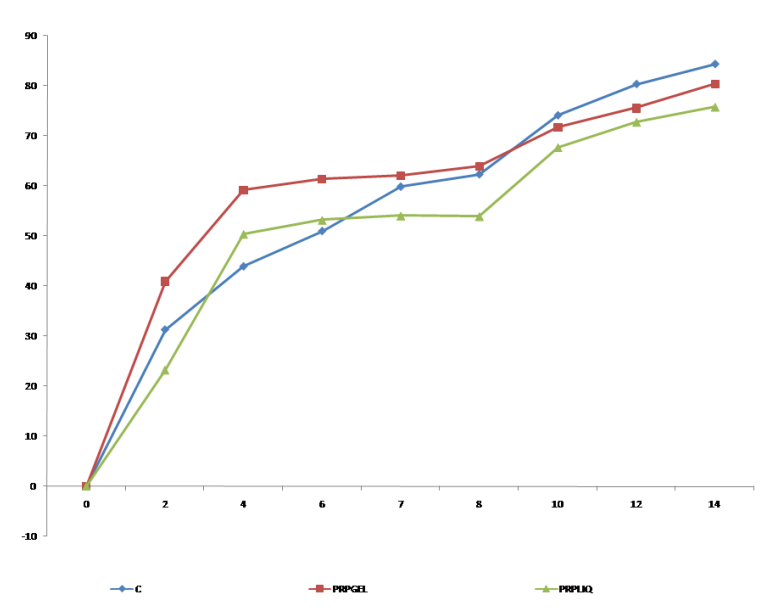

Figure 2. Average contraction rate (\%) increase from each group "versus" observation days. Difference between treatments can be observed until day 6 , whereas by the end of evaluation there are no more differences.

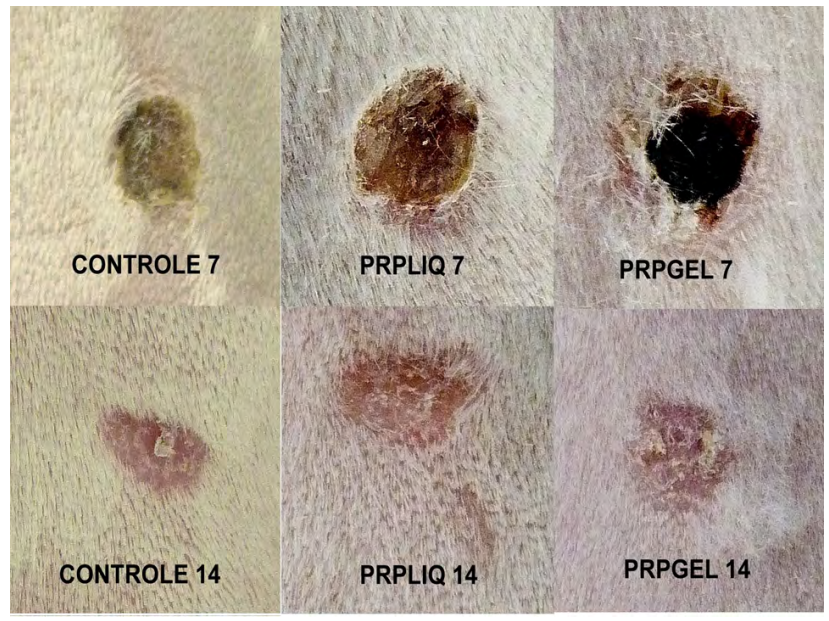

Figure 3. Clinical evaluations. Lesions view on clinical evaluations at days 7 and 14 post-surgery. At $14^{\text {th }}$ day all groups exhibited similar rates in injury healing.
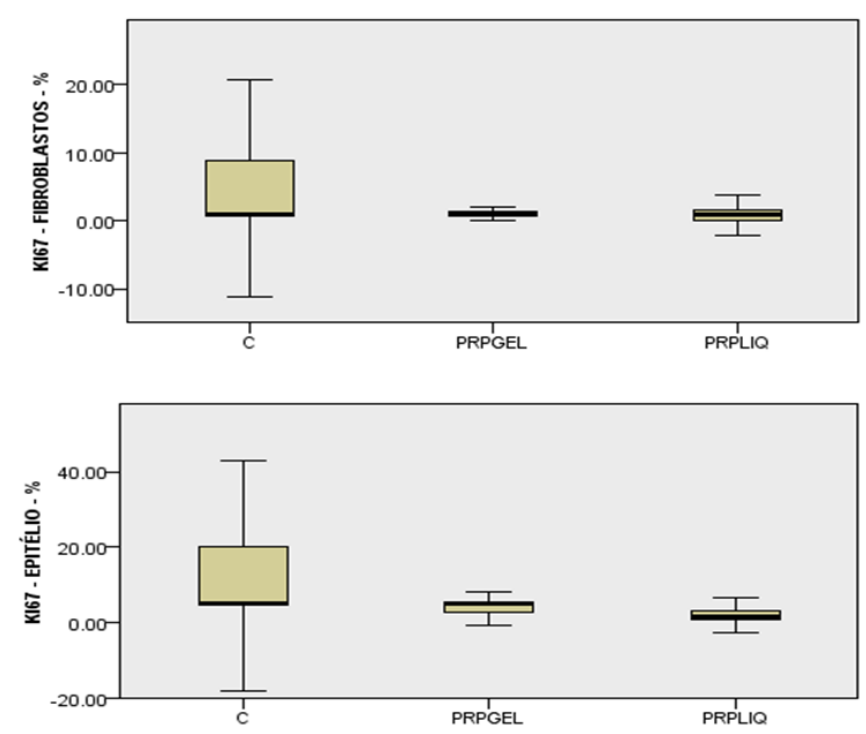

Figure 4. Immunohistochemistry parameters (epithelial and fibroblastic proliferation). There is significant difference between means of LIQPRP group and CG at evaluation day 14.

\section{DISCUSSION}

The main concern about employment of a product derived from the animal itself was due to possibility of immunological reaction associated to platelet membrane antigens, which could lead to growth factors secretion inability, and therefore in a therapeutic effect failure. These circumstances were also addressed by other studies [8]. Concerning the possibility of clinical application, utilization of an autologous product can avoid infectious diseases transmission, an important point to be considered not only for animals but also for human treatments [24].
PRP method utilized in this study was able to achieve platelet concentration higher than 1.000 .000 $\mu \mathrm{L}-1$, increasing, on average, 7.95 times basal values. This concentration is higher than previous described protocols $[1,12,15,26]$, which could not reach three times platelet concentration with patient's blood. Besides, we found higher concentration than those obtained by automatic methods, that raised levels one to four times physiological levels [11].

In the present study, there was a need to raise platelet poor plasma volume ( $2 \mathrm{~mL}$ collected fraction) in order to obtain autogenous thrombin required for gel 
PRP. After this modification, a stable and reasonable platelet concentration gel was produced. However, this form of PRP application requires more time for sample preparation, since it needs to become a gel, therefore increasing the production cost. Furthermore, injection of liquid PRP directly in the wound site activates platelets by generated substances due to needle perforation, and mainly due to tissue trauma generated at the lesion site [25].

Relating to the therapies administered, gel PRP was considered more manageable, since 3D structure could easily adapt to wound site after simply deposition of it. Liquid PRP was administered with needle $(0.7 \mathrm{X}$ $25 \mathrm{~mm})$ and syringe $(3 \mathrm{~mL})$, which required the surgeon to be more careful and perform a slow injection in order to avoid any spill and loss of material.

The study did not show any side effects or adverse reactions that could be attributed to PRP usage. PRP gel usage demonstrated not to elongate inflammatory phase and also not to produce any deleterious changes, such as necrotic tissue and foreign body reaction stimulus - these were previous concerns since gel PRP was a 3D biomaterial transplanted to wound site. Furthermore, histopathological analysis did not point any clot traces formed by gel PRP dehydration, although it is not possible to ensure that the clot was eliminated, reabsorbed, or even removed by the animal. Literature does not indicate any conclusive information regarding what happens to gel PRP fraction after its effect within the tissue.

Despite wound contraction rate had shown some improvement signals - i.e., elapsed time for healing - for GELPRP group on initial days of evaluation $(2,4$, and 6$)$, by the end of the experiment there was no difference between mean rates within treated groups. At day 14 - last day of experiment - all groups exhibited similar rates in injury healing. Indeed, regardless of several authors relates that they have found significant improvements in tissue healing and bone repairing using PRP, others did not notice the same benefits [15]. Different studies also could not demonstrate gel PRP efficiency in the treatment of injuries in experimental models $[8,14,16]$. Variations in some key features of PRP including platelet concentration, and coagulation activator, can alter PRP quality [2]. Platelet inability to secret growth factors, or even early release of them can be another reasonable explanation [4,11]. Morphological analysis of platelets on blood smear is highly recommended as a tool to evaluate product quality, because platelets have different morphology when activated, and display cytoplasmic elongations [15], however it can cause a great delay in product deliver. Moreover, material could have been submitted to flow cytometry [3]. Nevertheless, flow cytometry requires specialists, limiting employment of this technique. Inability of autogenous thrombin to activate platelets is also a possibility that could explain PRP therapeutic failure. To address this hypothesis, a study [19] suggested that when autogenous thrombin is being utilized, its concentration should be validated by amidolytic assay. This approach depends on thrombin quantification, therefore specific equipment and materials are needed, resulting in higher product cost and addition of steps for its achievement [20].

There is a hypothesis regarding growth factors overload causing dose dependent inhibitory effect. This can be questioned since LIQPRP group has reached unsatisfying results for contraction rate comparing to GELPRP group. LIQPRP group reached a mean of 8.64, while GELPRP mean value was 5.62 times basal values. Some studies analyzed PRP effectiveness in increasing tissue repair, relating their results with several administered platelet concentrations. Results have shown that PRP effectiveness may follow concentration dependence pattern, that is, really high concentrations might cause prejudicial effect [21], however there is still no consensus about what increment levels would be ideal and from what value there is no more benefit, and more importantly, when the product starts being prejudicial for healing process.

\section{CONCLUSIONS}

Based on results obtained in this study, PRP local administration did not accelerate the healing process upon morphometric evaluation 14 days after surgery, with the use of liquid PRP demonstrating lower epithelialization levels by histopathological evaluation compared to the Control group 14 days after surgery.

New studies exploring different diagnostic tools are highly recommended in order to better understand the results and provide improvements in current treatments.

\section{MANUFACTURER}

${ }^{1}$ Eppendorf® do Brasil Ltda., São Paulo, SP, Brazil. 
Acknowledgements. This work was supported by Fundo de Incentivo à Pesquisa (FIPE), Hospital de Clínicas de Porto Alegre and Conselho Nacional de Desenvolvimento Científico e Tecnológico (CNPq).

Ethical approval. All procedures were performed in accordance with the 11.794 (08/10/2008) Experimental Animal Management Brazilian Law. The study was approved by the Ethical Commit of Hospital de Clínicas de Porto Alegre (CEUA HCPA, 11-0359).
Declaration of interest. The authors report no conflicts of interest. The authors alone are responsible for content and writing of the paper.

\section{REFERENCES}

1 Anitua E. 1999. Plasma rich in growth factors: preliminary results of use in the preparation or future sites for implants. International Journal of Oral Maxillofacial Implant. 14(4): 529-535.

2 Anitua E., Sanchez M., Nurden A., Nurden P., Orive G. \& Andia I. 2006. New insights into and novel applications for platelet-rich fibrin therapies. Trends in Biotechnology. 24(5): 227-234.

3 Barroso C., Benito J. \& Puig A. 2007. Calidad del plasma rico en plaquetas: estúdio de la activación plaquetaria. Revista Española de Cirurgía Oral y Maxilofacial. 29(4): 240-248.

4 Eppley B., Woodell J. \& Higgins J. 2004. Platelet Quantification and Growth Factor Analysis from Platelet-Rich Plasma: Implication for Wound Healing. Plastic and Reconstructive Surgery. 114(6): 1502-1508.

5 Foster T.E., Puskas B.L., Mandelbaum B.R., Gerhardt M.B. \& Rodeo S.A. 2009. Platelet rich plasma: from basic science to clinical applications. American Journal of Sports Medicine. 37(11): 2259-2272.

6 Garcez T.N.A., Paz A.H.R., Magrisso A.B., Mello F., Gonçalves F.C., Meyer F.S., Contesini E.A. \& Cirne-Lima E.O. 2013. Comparison of Three Protocols to Obtain Platelet Rich Plasma (PRP) with Rabbits as Experimental Model. Acta ScientiaeVeterinariae. 41(1134): 1-7.

7 Hossein K., Sardari K., Emami M., Movassaghi A., Goli A., Lotfi A. \& Malekzadeh S. 2008. Efficacy of Autologous Platelet-Rich Plasma (PRP) Activated by Thromboplastin-D on the Repair and Regeneration of Wounds in Dogs. Iranian Journal of Veterinary Surgery. 3(4): 19-29.

8 Kazakos K., Lyras D., Verettas D., Tilkeridis K. \& Tryfonidis M. 2009. The use of autologous PRP gel as an aid in the management of acute trauma wounds. Injury. (40): 801-805.

9 Kevy S. \& Jacobson M. 2004. Comparison of methods for point of care preparation of autologous platelet gel. Journal of Extra-Corpor Technology. 36(1): 28-35.

10 Landsberg R., Roy M. \& Glickman R. 2000. Quantification of growth factor levels using a simplified method of platelet-rich plasma gel preparation. Journal of Oral and Maxillofacial Surgery. 58(1): 297-300.

11 Lopez J., Chimenos E., Sanchez J. \& Castañeda P. 2007. Plasma rico en factores de crecimiento y regeneración ósea. Dentum. 7(3): 108-112.

12 Maia L., Souza M., Ribeiro J., Oliveira A., Alves G., Benjamin L., Silva Y., Zandim B. \& Moreira J. 2009. Plateletrich plasma in the treatment of induced tendinopathy in horses: histologic evaluation. Journal of Equine Veterinary Science. 29(8): 618-626.

13 Marx E. 2001. Platelet-rich plasma (PRP): what is PRP and what is not PRP? Implant Dentistry. 10(4): 225-228.

14 Monteiro B.S., Argolo-Neto N.M. \& Del Carlo R.J. 2010. Células-tronco mesenquimais. Ciência Rural. 40(1): 238245.

15 Rebar A., MacWilliamns P., Feldman B. \& Frebar A. 2003. Plaquetas. In: Guia de hematologia para cães e gatos. São Paulo: Roca, pp.131-156.

16 Santoso S. 2003. Human platelet alloantigens. Transfusion and Apheresis Science. (28): 227-236.

17 Silva A. 2007. Plasma rico em plaquetas (PRP) associado ou não ao osso esponjoso autógeno no reparo de falhas ósseas experimentais. 32f. (Dissertação Mestrado Curso de Pós-graduação em Medicina Veterinária, Universidade Federal de Viçosa.

18 Vendramin F.S., Franco D., Nogueira C.M., Pereira M.S. \& Franco T.R. 2006. Plas $\neg$ ma rico em plaquetas e fatores de crescimento: técnica de obtenção e utilização em cirurgia plástica. Revista do Colégio Brasileiro de Cirurgiões. 33(1): 24-28. 
19 Vendramin F.S., Franco D. \& Franco R. 2009. Método de obtenção do gel de plasma rico em plaquetas autólogo. Revista Brasileira de Cirurgia Plástica. 24(2): 212-218.

20 Vendrúsculo P. 2012. Avaliação da eficácia de diferentes protocolos de preparo do Plasma Rico em Plaquetas para uso em Medicina Equina. Pesquisa Veterinária Brasileira. 32(2): 106-110.

21 Webrich G., Hansen T. \& Kleis G. 2004. Effect of platelet concentration in platelet rich plasma on peri-implant bone regeneration. Bone. 34(4): 665-671. 